\title{
Effect of Absorption-Desorption Cycles on Structure and Stability of Protides in Ti-Cr-V Alloys *1
}

\author{
Takashi Kazumi *2, Takuya Tamura, Atsunori Kamegawa, \\ Hitoshi Takamura and Masuo Okada \\ Department of Materials Science, Graduate School of Engineering, Tohoku University, Sendai 980-8579, Japan
}

\begin{abstract}
Ti-Cr-V alloys with a BCC structure have high protium capacities, but it is known that the cyclic properties for the alloys change with varying $\mathrm{V}$ content. In this paper, the cyclic properties of the Ti-Cr-V alloys are investigated in view of the crystal structure of the $\beta$ protide phase, which was measured at the point after desorbing at the plateau region and the thermal stability of the $\gamma$ protide phase, which was measured at the point immediately before desorbing at the desorption region. It was found that the crystal structure of the $\beta$ phase was changed from BCC phase to BCT phase and the $c / a$ increased with increasing the cycle number. This difference of the crystal structure of the $\beta$ phase suggests that the lattice can't gradually contract to $a$-axis direction at absorbing process with increasing the cycle number. Furthermore, it was found that the absorption-desorption cycle process causes the declined slope of the $\Delta H$ plots due to existence of the different $\gamma$ protides of different thermal stabilities. Namely, this result suggests that site energies of protium in the lattice have a distribution after absorption-desorption cycles.
\end{abstract}

(Received May 22, 2002; Accepted July 2, 2002)

Keywords: hydrogen storage alloy, titanium-chromium-vanadium alloy, $\beta$ protide phase, $\gamma$ protide phase, body centered cubic, body centered tetragonal, slope of $\Delta H$ plots

\section{Introduction}

Protium (hydrogen atom) storage alloys are proposed to be used as hydrogen storage tanks for fuel-cell automobiles. $\mathrm{Ti}-\mathrm{Cr}-\mathrm{V}$ alloys with a BCC structure, which are known to have about 3 mass\% effective protium capacity with desorbing at $373 \mathrm{~K}$, are regarded as one of the candidates for the media of hydrogen storage tanks. ${ }^{1-14)}$ In view of practical use of the alloys, it is important to know absorption-desorption cyclic properties and heat balance associated with protium absorption-desorption process.

Shirasaki et al. in our group reported that the particle size of the Ti-Cr-V alloy after 50th cycle became small with decreasing $\mathrm{V}$ content. ${ }^{15)}$ In their report, there are no studies on the crystal structure and the thermal stability of the protide phases. Thus, the cyclic properties were investigated in terms of the crystal structure and the thermal stability of the protide phases in this study. It is known that the magnitudes of the enthalpy changes $\Delta H$ for $\mathrm{AB}_{5}$ type alloys are constant throughout the plateau region. ${ }^{16)}$ However, there are few reports about $\Delta H$ on the BCC solid solution type alloys.

Therefore, the purpose of this study is to examine the crystal structure changes and the thermal stability changes of the protide phases for the $\mathrm{Ti}-\mathrm{Cr}-\mathrm{V}$ alloys with increasing the absorption-desorption cycles.

\section{Experimental Procedures}

$\mathrm{Ti}-\mathrm{Cr}-\mathrm{V}$ alloys were prepared by arc-melting on a watercooled copper hearth under an Ar atmosphere. The purities of the raw materials were as follows: $\mathrm{Ti}, \mathrm{Cr}>99.99$ mass $\%$; $\mathrm{V}>99.95$ mass $\%$. Samples were remelted five times to en-

\footnotetext{
${ }^{* 1}$ This paper was Presented at the Spring Meeting of the Japan Institute of Metals, held in Tokyo, on March 28, 2002.

${ }^{* 2}$ Graduate Student, Tohoku University.
}

sure their homogeneity. Heat-treatment was carried out under an Ar atmosphere. The samples were annealed at $1673 \mathrm{~K}$ for $1 \mathrm{~h}$, and then quenched into iced-water.

Crystal structures were determined by X-ray diffractometer (XRD) with $\mathrm{Cu}-\mathrm{K} \alpha$ radiation. The Pressure-Compositionisotherms (PCT curves) were measured with a Sieverts-type apparatus at $293-353 \mathrm{~K}$ for $\mathrm{Ti}: \mathrm{Cr}=2: 3$ alloys, at $363-423 \mathrm{~K}$ for $\mathrm{Ti}: \mathrm{Cr}=1: 1$ alloys, at $423-523 \mathrm{~K}$ for $\mathrm{Ti}: \mathrm{Cr}=3: 2$ alloys respectively. The magnitudes of the enthalpy changes $\Delta H$ for the plateau versus protium concentration were determined from the van't Hoff plots. The magnitudes of the $\Delta H$ were evaluated in 1st cycle (after dehydrogenation following activated treatment) and 31th cycle for all alloys. The dehydrogenation treatment were performed for the purpose of appearing the original plateau pressure of the alloys that are independent of cooling rate in the condition at $673 \mathrm{~K}$ for $1 \mathrm{~h}$ for $\mathrm{Ti}: \mathrm{Cr}=2: 3,1: 1$ alloys and at $773 \mathrm{~K}$ for $1 \mathrm{~h}$ for $\mathrm{Ti}: \mathrm{Cr}=3: 2$ alloy.

The effective protium capacity was defined as a difference between protium absorbing capacity at hydrogen gas pressure of $7 \mathrm{MPa}$ and that at $0.01 \mathrm{MPa}$ in desorbing process. The hysteresis factor was defined as $\ln \left(P_{\mathrm{a}} / P_{\mathrm{d}}\right)$, where $P_{\mathrm{a}}$ is the plateau pressure in absorption process and $P_{\mathrm{d}}$ is the plateau pressure in desorption process.

\section{Results and Discussion}

\subsection{Effect of cycles on the crystal structure of $\boldsymbol{\beta}$ protide phase}

It has been found by XRD that all studied alloys has a BCC single phase.

Figure 1 shows $\mathrm{P}-\mathrm{C}$ isotherms for $\mathrm{Ti}-\mathrm{Cr}-20$ at $\% \mathrm{~V}(\mathrm{Ti}: \mathrm{Cr}=$ 2:3) alloy (at \% is abbreviated hereafter) in 1st, 31th and 101th cycle. The maximum protium absorption capacity for $1 \mathrm{st}$ cycle shows about 3.6 mass $\%$ protium. The effective pro- 


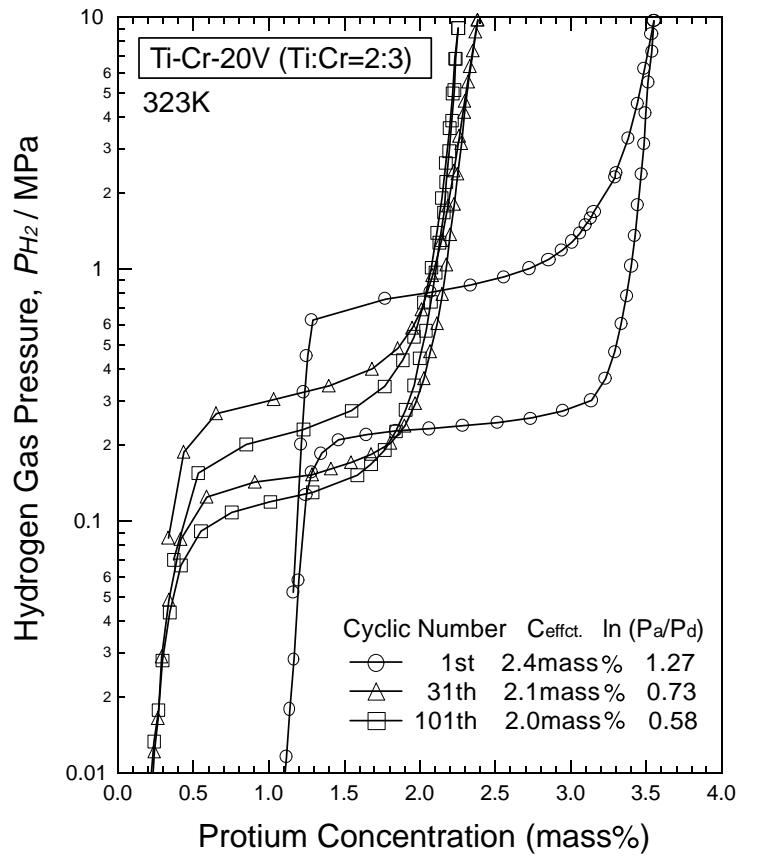

Fig. 1 P-C isotherms at $323 \mathrm{~K}$ for $\mathrm{Ti}-\mathrm{Cr}-20 \mathrm{~V}(\mathrm{Ti}: \mathrm{Cr}=2: 3)$ alloy from 1 st to 101 th cycle. $C_{\text {effec. }}$ is represented as effective protium capacity.

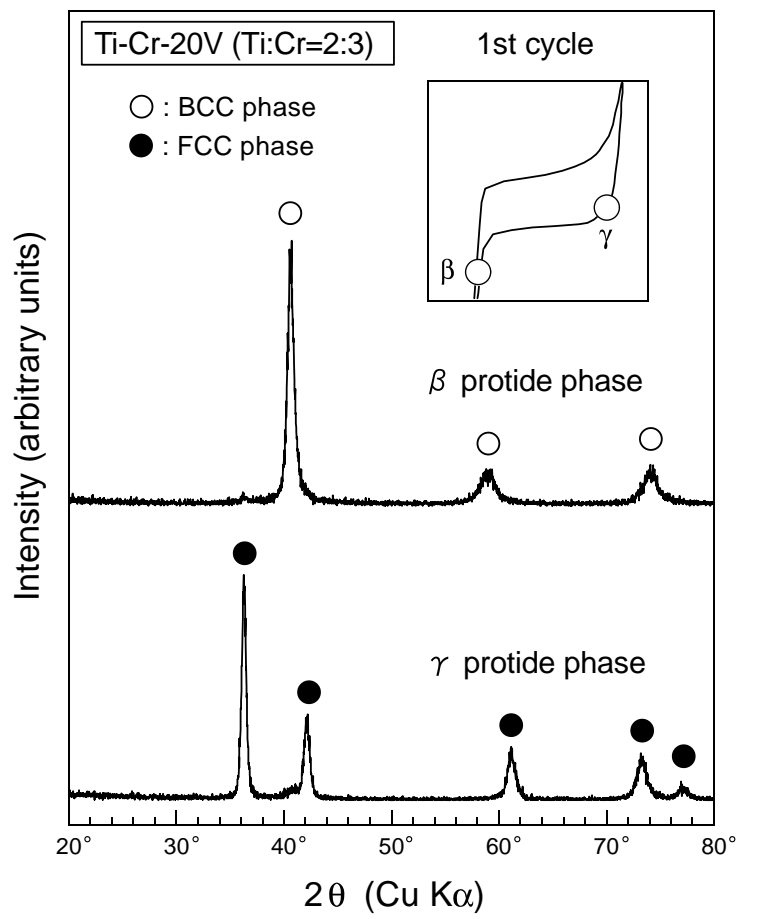

Fig. 2 XRD patterns of several protide phases for the $\mathrm{Ti}-\mathrm{Cr}-20 \mathrm{~V}$ (Ti:Cr $=2: 3)$ alloy at 1 st cycle.

tium desorption capacity, $C_{\text {effec. }}$, for 1 st cycle shows about 2.4 mass \% protium. However, the effective protium desorption capacity decreased with increasing the absorptiondesorption cycle number as follows: 31 th; 2.1 mass $\%$, 101th; 2.0 mass \%. Furthermore, the shape of the P-C isotherms for the alloy was changed and the hysteresis factor, $\ln \left(P_{\mathrm{a}} / P_{\mathrm{d}}\right)$, decreased with increasing the cycle number as follows: 1st; $1.27,31$ th; $0.73,101$ th; 0.58 .

Figure 2 shows XRD patterns of several protide phases for the $\mathrm{Ti}-\mathrm{Cr}-20 \mathrm{~V}(\mathrm{Ti}: \mathrm{Cr}=2: 3)$ alloy. The protide phases were

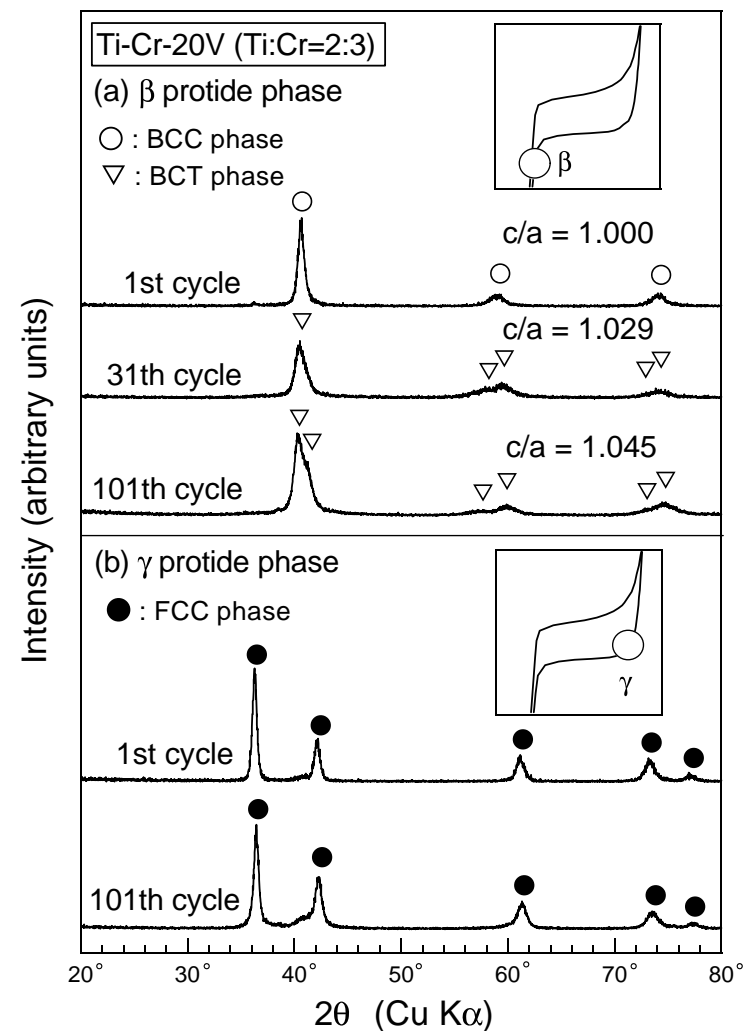

Fig. 3 (a) XRD patterns of $\beta$ protide phase (b) XRD patterns of $\gamma$ protide phase for the Ti-Cr-20V ( $\mathrm{Ti}: \mathrm{Cr}=2: 3$ ) alloy from 1st to 101th cycle.

measured by XRD at two points of P-C isotherms as follows: $\beta$ phase was measured at the point after desorbing at the desorption plateau region, $\gamma$ phase was measured at the point immediately before desorbing at the desorption plateau region. The crystal structure of the $\beta$ phase was BCC single phase and the crystal structure of the $\gamma$ phase was FCC single phase at 1 st cycle. Figure 3(a) shows XRD of the $\beta$ protide phases for the $\mathrm{Ti}-\mathrm{Cr}-20 \mathrm{~V}$ ( $\mathrm{Ti}: \mathrm{Cr}=2: 3$ ) alloy from 1st to 101th cycle. It was found that the crystal structure of the $\beta$ phase was changed from BCC phase to BCT phase and the $c / a$ increased with increasing the cycle number. Figure 3(b) shows XRD of the $\gamma$ protide phases for the $\mathrm{Ti}-\mathrm{Cr}-20 \mathrm{~V}(\mathrm{Ti}: \mathrm{Cr}=2: 3)$ alloy from 1 st to 101 th cycle. It was found that the $\gamma$ phase was maintained as FCC phase and the lattice parameter was almost constant with increasing the cycle number. Figure 4 shows lattice parameter changes and the schematic illustration of the crystal structures for several protide phases shown in Fig. 3. The $\gamma$ phase are considered to be a BCT unit cell in two FCC unit cells. As shown in Fig. 4 , the $\beta \leftrightarrows \gamma$ transformation in 1st cycle was $\mathrm{BCC}(\beta) \leftrightarrows \mathrm{FCC}(\gamma)$ transformation, thus the lattice must contract along $a$-axis direction at absorbing process and expand along $a$-axis direction at desorbing process as opposed to $c$-axis direction. With increasing the cycle number, however, the $\beta \leftrightarrows \gamma$ transformation in 101th cycle was $\mathrm{BCT}(\beta) \leftrightarrows \mathrm{FCC}(\gamma)$ transformation. This difference of the $\beta \leftrightarrows \gamma$ transformation suggests that the lattice can't gradually contract along $a$-axis direction at absorbing process with increasing the cycle number. We reported that the magnitudes of the lattice parameter changes to $a$-axis direction appear to be correlation with the hysteresis factor shown in Fig. 1. ${ }^{17)}$ Namely, the major reason of the decrease 


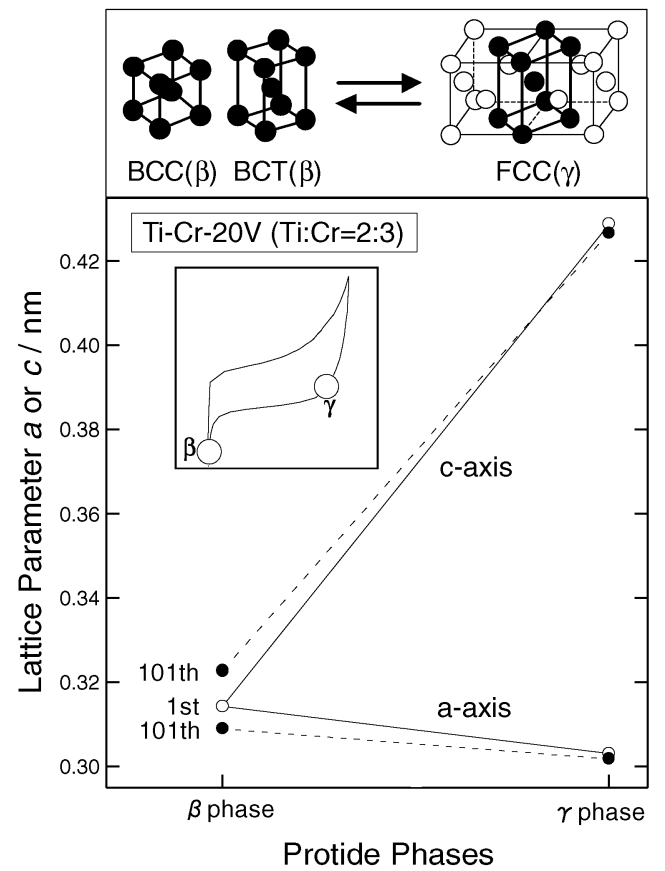

Fig. 4 Lattice parameter changes and schematic illustration with the $\beta \leftrightarrows \gamma$ transformation for the $\mathrm{Ti}-\mathrm{Cr}-20 \mathrm{~V}(\mathrm{Ti}: \mathrm{Cr}=2: 3)$ alloy from $1 \mathrm{st}$ to 101 th cycle.

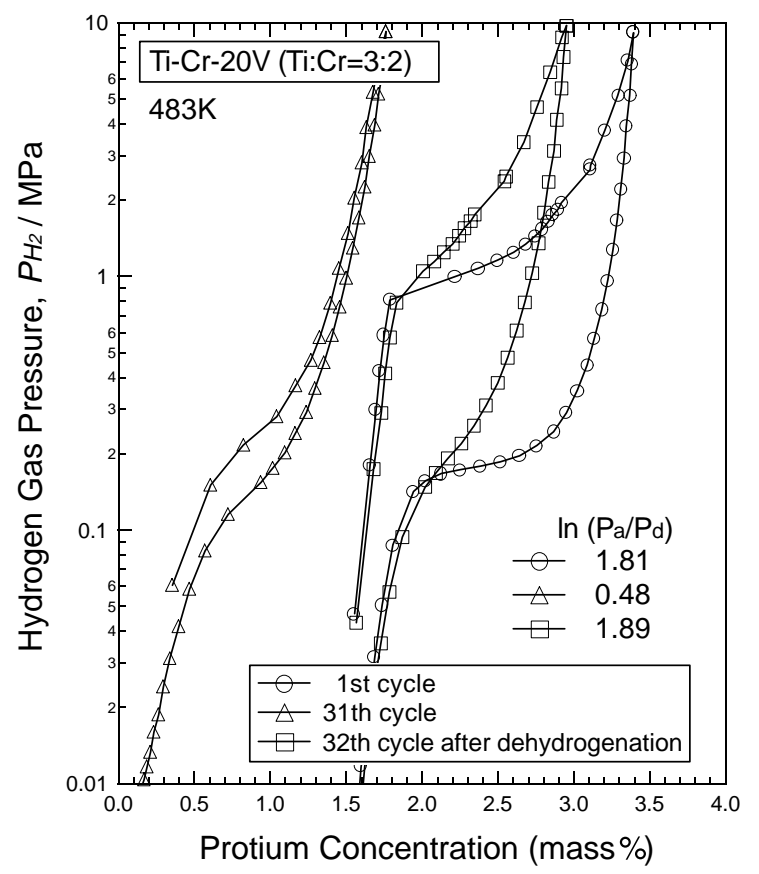

Fig. 5 P-C isotherms at $483 \mathrm{~K}$ for the $\mathrm{Ti}-\mathrm{Cr}-20 \mathrm{~V}(\mathrm{Ti}: \mathrm{Cr}=3: 2)$ alloy from 1 st to 31 th cycle and 32 th cycle after dehydrogenation following 31 th cycle.

of the hysteresis factor with increasing the cycle number is considered to be such that the lattice hardly contracts along $a$-axis direction when $\operatorname{BCT}(\beta) \rightarrow \operatorname{FCC}(\gamma)$ transformation takes place at absorbing process.

Figure 5 shows $\mathrm{P}-\mathrm{C}$ isotherms for the $\mathrm{Ti}-\mathrm{Cr}-20 \mathrm{~V}$ (Ti: $\mathrm{Cr}=$ 3:2) alloy from 1 st to 31 th cycle and 32th cycle after dehydrogenation following 31 th cycle. The dehydrogenation treatment was performed in the condition of evacuation by rotary pomp at $773 \mathrm{~K}$ for $1 \mathrm{~h}$. The plateau of the P-C isotherms in

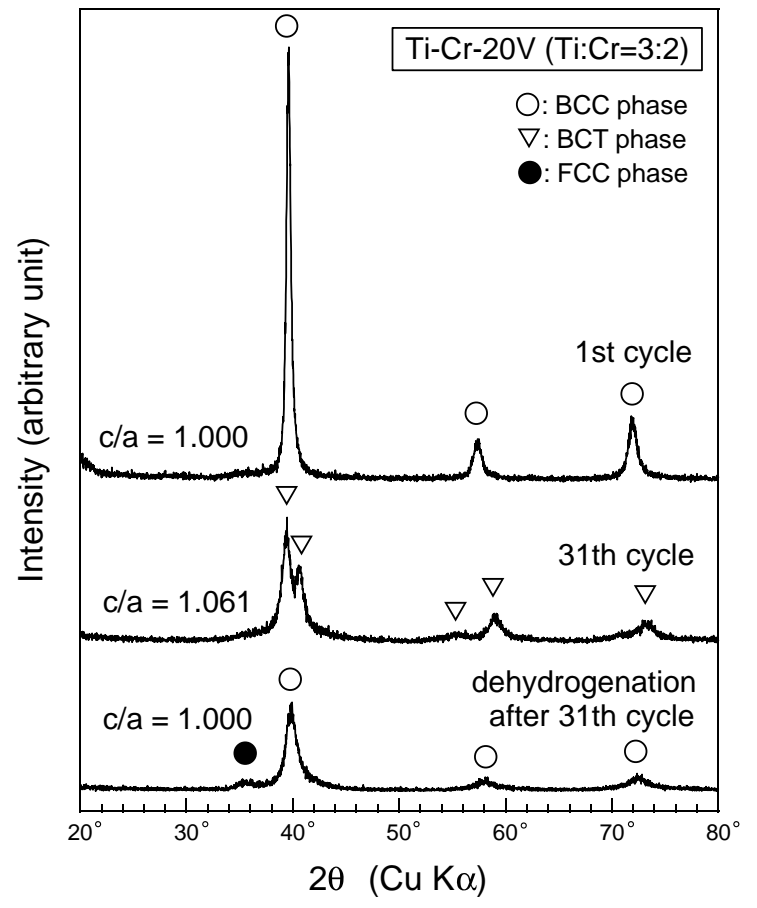

Fig. 6 XRD patterns of the $\beta$ protide phase in several cycle numbers and after dehydrogenation for the $\mathrm{Ti}-\mathrm{Cr}-20 \mathrm{~V}(\mathrm{Ti}: \mathrm{Cr}=3: 2)$ alloy.

31th cycle remarkably inclined in comparing with the plateau for the $\mathrm{Ti}-\mathrm{Cr}-20 \mathrm{~V}(\mathrm{Ti}: \mathrm{Cr}=2: 3)$ alloy in same cycle as shown in Fig. 1. Furthermore, the hysteresis of the P-C isotherms in 31th cycle was very small as shown in Fig. 5. However, it was found that the plateau pressure and the hysteresis of the P-C isotherms in 32th cycle after dehydrogenation following 31th cycle were recovered. The increment of the plateau pressure by dehydrogenation may be that some accumulated lattice defects induced by absorption-desorption cycles were annealed out. Figure 6 shows XRD patterns of the $\beta$ phase in several cycle numbers corresponding to the $\mathrm{P}-\mathrm{C}$ isotherms shown in Fig. 5. The crystal structure of the $\beta$ phase in 31th cycle was BCT phase. On the other hand, it was found that the crystal structure of the $\beta$ phase in 32th cycle after dehydrogenation following 31th cycle returned to be a BCC phase. The major reasons of this result are considered as follows: dehydrogenation treatment decreases some amount of defects as well as complete desorption of protium. Although it is unclear which factor dominates to determine the crystal structure, some amount of defects still remains in the alloy as shown in Fig. 6, where the diffracted peak in 32th cycle was broad as before. BCC structure may be appeared by complete desorption of protium. Therefore, these result suggests that the recovery of the hysteresis in 32th cycle originates in the $\mathrm{BCC}(\beta) \leftrightarrows \mathrm{FCC}(\gamma)$ transformation.

\subsection{Effect of cycles on the thermal stability of $\gamma$ protide phase}

Figure 7 shows the magnitudes of the enthalpy changes $\Delta H$ at desorption process versus protium concentration throughout the plateau region of the P-C isotherms for the Ti-Cr-20V (Ti:Cr $=2: 3,1: 1,3: 2$ ) alloys. The zero point of protium concentration is fixed to be the same point in several cycles. The magnitudes of $\Delta H$ increased with increasing 


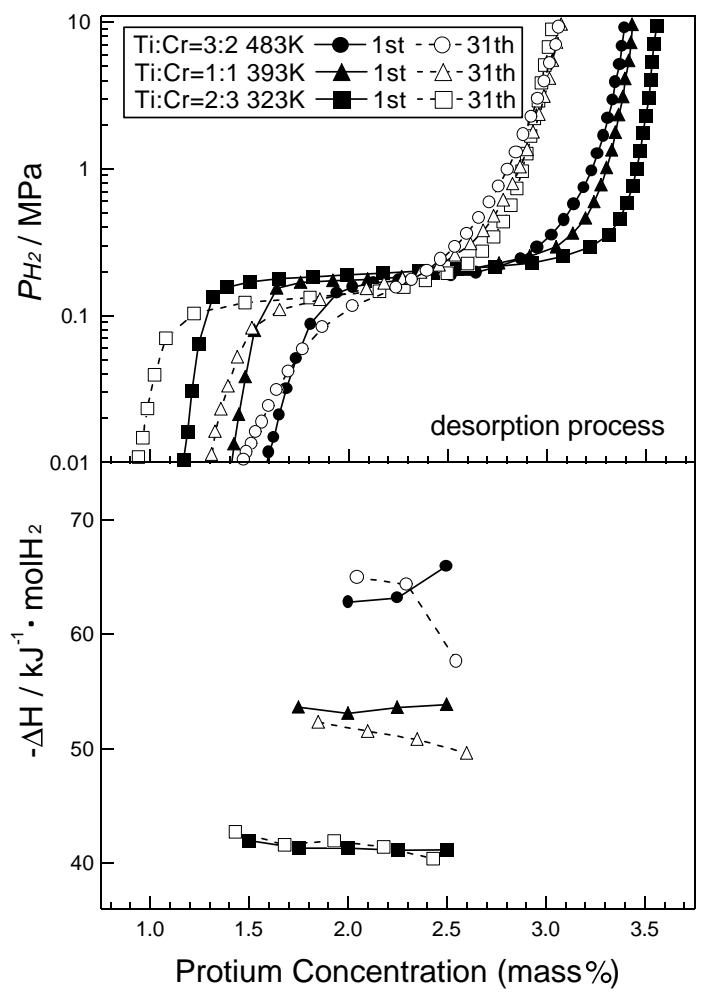

Fig. 7 Enthalpy changes at desorption process $\Delta H$ versus protium concentration throughout the plateau region of the $\mathrm{P}-\mathrm{C}$ isotherms for the Ti-Cr-20V (Ti:Cr = 2:3, 1:1, 3:2) alloys.

Ti content in 1st cycle as follows; $\Delta H=41.4 \mathrm{~kJ} / \mathrm{mol} \mathrm{H}_{2}$ (Ti: $\mathrm{Cr}=2: 3), \Delta H=52.5 \mathrm{~kJ} / \mathrm{mol} \mathrm{H} \mathrm{H}_{2}(\mathrm{Ti}: \mathrm{Cr}=1: 1), \Delta H=$ $64.6 \mathrm{~kJ} / \mathrm{mol} \mathrm{H}_{2}(\mathrm{Ti}: \mathrm{Cr}=3: 2)$. Furthermore, it was found that the magnitudes of $\Delta H$ were almost constant throughout the plateau region in 1st cycle, while the magnitudes of $\Delta H$ in 31th cycle reduce with increasing protium concentration. This tendency is remarkable with increasing Ti content and the measurement temperature of the P-C isotherms. The 30th absorption-desorption cycle process cause the declined slope of the $\Delta H$ plots due to existence of the different $\gamma$ protides of different stabilities. Namely, this result suggests that the energies of protium for occupying crystal sites have a distribution after 30th cycles, because the $\Delta H$ plots for as-cast alloy declines compared with the flat $\Delta H$ plots for heat-treated alloy as shown in Fig. 8. This result for as cast alloy in Fig. 8 is due to the inhomogeneous distribution of the constituent atoms, namely that protium occupies Ti-rich interstitial sites at low protium concentration, while protium gradually occupies $\mathrm{Cr}$ rich interstitial sites with increasing protium concentration.

It is known to improve the cyclic properties with increasing $\mathrm{V}$ content for the Ti-Cr-V alloys in our recent work. ${ }^{15)}$ Thus, to investigate the slope of $\Delta H$ plots after 30th cycles for V-rich alloys, the magnitudes of $\Delta H$ for the Ti-Cr- $x \mathrm{~V}$ (Ti: $\mathrm{Cr}=2: 3 ; x=20,40,60,80)$ alloy in 31 th cycle was examined as shown in Fig. 9. It was found that the $\Delta H$ plots in 31 th cycle become flat with increasing $\mathrm{V}$ content. Therefore, the slope of $\Delta H$ plots is considered as one of factors to evaluate the cyclic property for protium storage alloys.

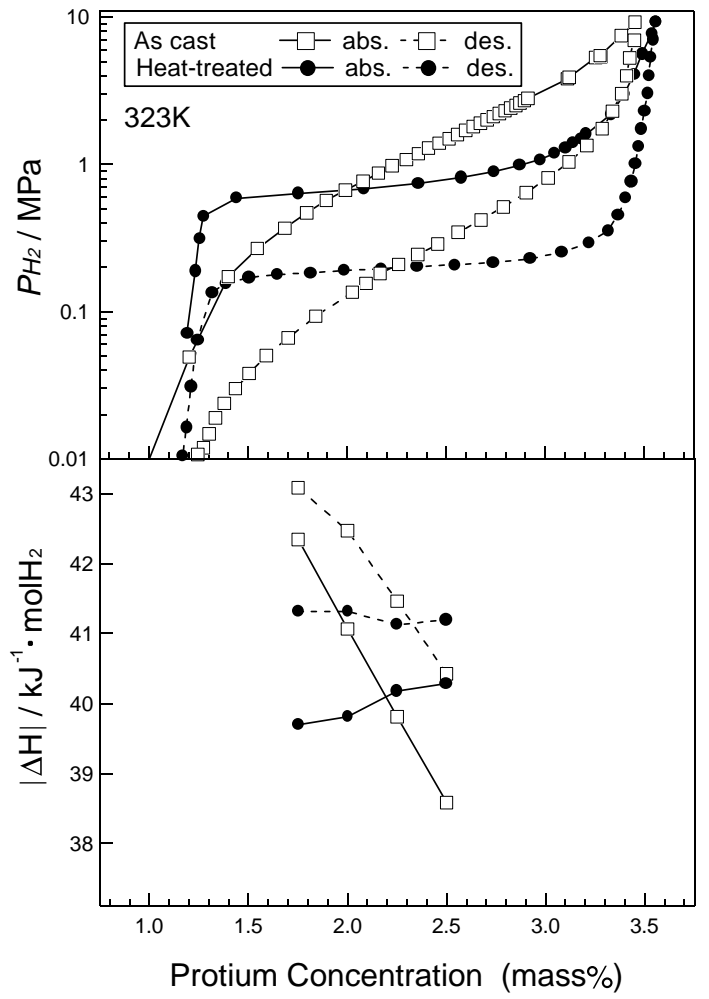

Fig. 8 Enthalpy changes $\Delta H$ versus protium concentration throughout the plateau region of the $\mathrm{P}-\mathrm{C}$ isotherms for the as-cast and heat-treated $\mathrm{Ti}-\mathrm{Cr}-20 \mathrm{~V}(\mathrm{Ti}: \mathrm{Cr}=2: 3)$ alloys.

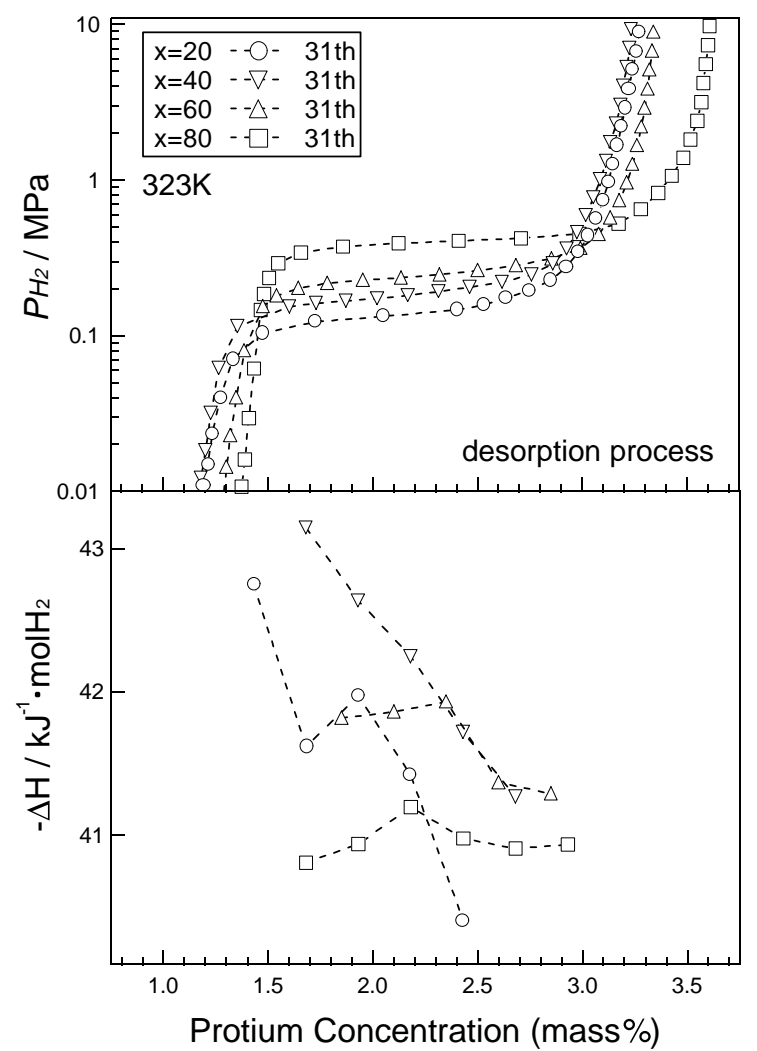

Fig. 9 Enthalpy changes at desorption process $\Delta H$ versus protium concentration throughout the plateau region of the P-C isotherms for the Ti-Cr- $x \mathrm{~V}$ (Ti:Cr $=2: 3 ; x=20,40,60,80$ ) alloys in 31 th cycle. 


\section{Conclusions}

Effect of the absorption-desorption cycles on the structure and the stability of protides in the $\mathrm{Ti}-\mathrm{Cr}-\mathrm{V}$ alloys have been investigated and the following conclusions have been derived.

(1) The crystal structure of the $\beta$ protide phase was changed from BCC phase to BCT phase and the $c / a$ increased with increasing the cycle number.

(2) The absorption-desorption cycle process causes the declined slope of the $\Delta H$ plots due to existence of the different $\gamma$ protides of different thermal stabilities.

\section{Acknowledgements}

This work has been supported in part by a Grand-in-Aid for Scientific Research on Priority Area A of "New Protium Function" from the Ministry of Education, Culture, Sports, Science and Technology.

\section{REFERENCES}

1) H. Iba: Ph. D. Dissertation, (Tohoku Univ. Japan, 1997) (in Japanese).

2) T. Tamura, T. Kuriiwa, T. Amemiya, T. Fuda, A. Kamegawa, H. Takamura and M. Okada: Mater. Trans., JIM 40 (1999) 431-434.

3) Y. Tominaga, S. Nishimura, T. Amemiya, T. Fuda, T. Tamura, T.
Kuriiwa, A. Kamegawa and M. Okada: Mater. Trans., JIM 40 (1999) 871-874.

4) T. Kuriiwa, T. Tamura, T. Amemiya, T. Fuda, A. Kamegawa, H. Takamura and M. Okada: J. Alloys Compd. 293-295 (1999) 433-436.

5) T. Fuda, K. Matsumoto, Y. Tominaga, T. Tamura, T. Kuriiwa, A. Kamegawa and M. Okada: Mater. Trans., JIM 41 (2000) 577-580.

6) Y. Tominaga, K. Matsumoto, T. Fuda, T. Tamura, T. Kuriiwa, A. Kamegawa, H. Takamura and M. Okada: Mater. Trans., JIM 41 (2000) 617-620.

7) M. Okada, T. Kuriiwa, T. Tamura, H. Takamura and A. Kamegawa: Metals and Materials-Korea, 7 (2001) 67-72.

8) T. Tamura, Y. Tominaga, K. Matsumoto, T. Fuda, T. Kuriiwa, A. Kamegawa, H. Takamura and M. Okada: J. Alloys Compd. 330-332 (2002) 522-525.

9) M. Okada, T. Kuriiwa, T. Tamura, H. Takamura and A. Kamegawa: J. Alloys Compd. 330-332 (2002) 511-516.

10) T. Tamura, A. Kamegawa, H. Takamura and M. Okada: Mater. Trans. 42 (2001) 1862-1865.

11) T. Tamura, A. Kamegawa, H. Takamura and M. Okada: Mater. Trans. 43 (2002) 410-413.

12) H. Iba and E. Akiba: J. Alloys Compd. 253 (1997) 21-24.

13) H. Iba and E. Akiba: J. Alloys Compd. 231 (1995) 508-512.

14) E. Akiba and H. Iba: Intermetallics 6 (1998) 461-470.

15) K. Shirasaki, T. Tamura, T. Kuriiwa, T. Goto, A. Kamegawa, H. Takamura and M. Okada: Mater. Trans., to be published.

16) S. Luo, W. Luo, J. D. Clewley, T. B. Franagan and R. C. Bowman, Jr.: J. Alloys Compd. 231 (1995) 473-478.

17) T. Tamura, T. Kazumi, Y. Katano, A. Kamegawa, H. Takamura and M. Okada: Mater. Trans., to be published. 